\title{
Effects of different mark-up drug policies on drug-related expenditures in tertiary public hospitals: an interrupted time series study in Shanghai, China, 2015-2018
}

\author{
Xianji Wang ${ }^{1, \S}$, Fen Li $^{2, \S}$, Xuemei Wang ${ }^{3}$, Xinping Zhang ${ }^{3}$, Chenxi Liu ${ }^{3}$, Dan Wang ${ }^{3}$, \\ Haiyin Wang ${ }^{2}$, Yingyao Chen ${ }^{1, *}$ \\ ${ }^{1}$ Key Lab of Health Technology Assessment, National Health Commission, School of Public Health, Fudan University, Shanghai, China; \\ ${ }^{2}$ Shanghai Health Development Research Center, Shanghai, China; \\ ${ }^{3}$ School of Medicine and Health Management, Tongji Medical College of Huazhong University of Science and Technology, Wuhan, Hubei, China.
}

SUMMARY Irrational use of drugs remains a major challenge especially in developing countries, which contributed to a heavy pharmaceutical expenditure burden. Price regulation has been taken to curb the growth of pharmaceutical expenditures in many countries. This study aimed to investigate the impact of different mark-up drug policies on drug-related expenditures in tertiary public hospitals in Shanghai, China. Data were drawn from the audited financial statement in 24 tertiary public hospitals in Shanghai from January 2015 to December 2018. Drug-related revenue data and per capita cost data pre- and post-intervention were included. Interrupted time series design was applied to assess the actual effects of Fixed Percent Mark-up Drug (FPM) policy and Zero Mark-up Drug (ZMD) policy respectively. Results showed that ZMD policy achieved better intervention effects on declining drug-related expenditures than FPM policy. Apart from a declining trend in drug proportion (coefficient $=-0.0017, p=0.031$ ), no other significant changes were found during FPM implementation. However, ZMD policy was associated with a level decline in per capita outpatient drug cost (coefficient $=-12.21, p=0.025$ ) and a trend decline in per capita inpatient drug cost (coefficient $=-25.12, p<0.001)$, as well as a level decrease (coefficient $=-0.0256, p=0.001$ ) and a downward tendency (coefficient $=-0.0018, p<0.001$ ) in drug proportion. ZMD policy was effective in regulating drug-related expenditures, while FPM policy was difficult to achieve expected results due to the existence of profit space. Further regulation should be strengthened in the future, especially on drug revenue and per capita drug cost.

Keywords Zero Mark-up Drug policy, Fixed Percent Mark-up Drug policy, drug revenue, per capita drug cost, drug proportion

\section{Introduction}

Irrational use of drugs remains a widespread concern worldwide, especially in developing countries, where around $60 \%$ of drugs prescribed and sold in public health institutions were inappropriate $(1,2)$. It was reported that irrational use of drugs contributed to a heavy pharmaceutical expenditure burden and the costs resulted from harmful effects after taking drugs were up to 870 million USD per year in the UK (3). Pharmaceutical expenditure was assumed to account for $25 \%-70 \%$ of total healthcare expenditures in developing countries and approximately $10 \%$ in most developed countries (4). In OECD countries, the pharmaceutical expenditure was estimated to be approximately 800 billion USD, accounting for $17 \%$ of total healthcare expenditures, with the range of less than $10 \%$ in Denmark to more than $30 \%$ in Hungary (5). For Japan and South Korea, pharmaceutical expenditure constituted $20.6 \%$ and $25.1 \%$ of total healthcare expenditure respectively $(6,7)$.

In China, government investment was replaced by pharmaceutical profits, which became the major income source for hospitals for a long time (2). The overall healthcare expenditure increased almost sevenfold from approximately 75 billion USD to 519 billion USD since 2000, among which pharmaceutical expenditure was estimated to account for $42.5 \%$ and tertiary public hospitals was much higher (7). As one of the most common problems of irrational drug 
use, unnecessary drug use is serious in China (8-10). A close interest relationship between drug sales and prescriptions made unnecessary prescriptions and drug rebates prevail in the long term (11). Physicians in China tend to rely heavily on drug revenue due to the existence of profit margins on drugs (12). They have financial incentives to recommend patients drug therapies even when not appropriate, while patients are generally unable to judge whether the recommended drugs are suitable, which provides a shortcut for physicians to prescribe and profit from unnecessary medications $(13,14)$.

To curb the increasing growth of pharmaceutical expenditures, price regulation was put forward in many countries by setting, agreeing and cutting prices of drugs, aimed at increasing accessibility and restraining exorbitant prices $(5,15-18)$. Separation of prescribing and dispensing was one of the essential price regulation measures, which has originally been formed since the $12^{\text {th }}$ century and followed and adopted by numerous countries (19). For instance, in Korea, separation of drug prescribing from dispensing was implemented with the goal of fundamentally changing the inefficient provision and consumption of drugs to contain pharmaceutical expenditure (13). This approach could also help to decrease irrational drug use with the fact that prescriptions from dispensing physicians was twice and 7 times more than those by non-dispensing physicians in Zimbabwe and Malaysia, respectively $(20,21)$. Similar price regulation methods could also be seen in Spain, where a new system for fixing prices was adopted and a Ministerial Decree for selective reimbursement of drugs was introduced by government, to keep increasing pharmaceutical expenditures under control (22).

In China, declining mark-up on drugs was undertaken as part of a separation of healthcare and medicine policy, so as to decouple provider compensation from the prescription and sales. There are two typical mark-up drug policies, one is Fixed Percent Mark-up Drug (FPM) policy, which allows drugs to be sold on fixed mark-up percent based on the purchase price; the other is Zero Mark-up Drug (ZMD) policy, which requires all public hospitals to prescribe drugs at purchase price without including a mark-up (23). Previous studies mostly presented positive effects on healthcare expenditures shortly after implementing ZMD policy, but showed mixed results regarding long-term effects $(11,14,24)$. Regarding FPM policy, hospitals were found to show more preference for expensive drugs, which led to increasing healthcare expenditures and high drug revenue proportion in both outpatient and inpatient healthcare revenue $(9,25)$. Different from others, mark-up-cancellation policy in Shanghai, China was gradually executed by declining $5 \%$ of mark-up step by step, until all the mark-up was eventually cancelled. Specially, FPM policy with a mark-up decline from $15 \%$ to $10 \%$ was attempted to be executed initially, followed by the final implementation of ZMD policy. The focus of ZMD policy was completely decoupling provider compensation from the prescription and sales and thus eliminated physicians' incentive for prescribing expensive drugs and reducing excessive household spending on irrational drugs.

Previous practices mainly directly focused on one-time implementation of cancelling mark-up, but ignored the gradually executed process. Additionally, previous studies mainly focused on primary care settings and have reported varying and sometimes conflicting results which may result from different study designs, e.g. cross-sectional or before-after study designs (14). Few applied interrupted time series to simultaneously evaluate the actual effects of different mark-up drug policies, especially those represented by ZMD and FPM. A simultaneous comparison between the intervention effects brought by these two typical regulation measures (intervention with mark-up vs. intervention without mark-up) were deficient until now.

This study aimed to investigate the impact of ZMD policy and FPM policy on drug-related expenditures and provide a foundation for policy and practice improvements to avoid physicians' irrational prescriptions and improve patients' drug affordability. We sought to assess different regulation intensity on pharmaceutical expenditure, with specific attention towards identifying different intervention effects caused by ZMD policy and FPM policy respectively, so as to provide more evidence-based experience for international practice in tertiary public hospital settings.

\section{Materials and Methods}

\subsection{Setting}

This study was set in Shanghai municipality, which is located on the Yangtze River Delta in east China and covered a provincial coastal area of $6,340 \mathrm{~km}^{2}$. There are 24.18 million inhabitants in Shanghai (2017). The per capita GDP in Shanghai was 18,756 USD (2017), which was more than twice the average national per capita GDP (8,836 USD) and exceeded the high-income country threshold (12,235 USD). The life expectancy in Shanghai is estimated to be 83.37 years, like those in high-income countries (26-28). Public hospitals are responsible for majority of healthcare provision and account for appropriately $95 \%$ of all outpatient visits, inpatient discharges and inpatient surgical procedures (29). Among public hospitals, primary healthcare institutions provide essential medical care services, mainly including outpatient care as well as public health services, such as health education, maternity care, planned immunization, etc. (30). Secondary and 
tertiary public hospitals provide both outpatient and inpatient care, among which tertiary public hospitals serve as a medical service center within a region and provide nearly half of the outpatient care as well as $42.5 \%$ of inpatient services $(29,31)$.

In this study, all municipal tertiary public hospitals in Shanghai were selected for analysis, excluding the hospitals affiliated with the National Health Commission of the People's Republic of China. A total of twenty-four tertiary public hospitals were analyzed, including 9 Comprehensive hospitals, 4 Chinese medicine hospitals, and 11 Specialized hospitals, which accounted for $48.0 \%$ of all tertiary public hospitals, and $13.1 \%$ of all public hospitals in Shanghai. The scale of these 24 hospitals is large, whose number of beds, outpatients and inpatients account for $22.4 \%$, $22.2 \%$ and $37.5 \%$ of all public hospitals in Shanghai, respectively (Table 1 ).

\subsection{Policy Intervention}

From December, 2015 to February, 2017, gradual policy intervention aiming at reducing drug price were continuously implemented in Shanghai, by declining $5 \%$ of mark-up each time. The first formally intervention measure is declining the mark-up from $15 \%$ to $10 \%$ in December 10,2015 in all public hospitals (except for Chinese Herbal Medicine), and the actual procurement price over $500 \mathrm{RMB}$ should not exceed $50 \mathrm{RMB}$. The final powerful intervention was declining the drug mark-up to zero in February 1, 2017 in all public hospitals (except for Chinese Herbal Medicine), and being sold according to the actual procurement price, which represented ZMD policy was implemented.

From the first intervention to the final intervention, a significantly symbolic change was observed during the gradual intervention measures, that is a drug regulation policy of the FPM is experimentally and gradually replaced by ZMD from small-scale to fullscale. In this study, the first intervention measure of cancelling partial mark-up in December 10, 2015 and the final intervention of cancelling all markup in February 1, 2017 were selected into analysis, respectively representing the intervention with mark-up and without mark-up.

\subsection{Data sources and outcome indicators}

Data in this study were derived from the audited financial statement of each hospital. Monthly data of 24 tertiary public hospitals from January 2015 to December 2018 were collected, including drug-related revenue data and cost data.

Indicators concerning drug-related expenditures were designed and selected in this study, including drug revenue (total drug revenue, outpatient drug revenue and inpatient drug revenue), per capita outpatient drug cost, per capita inpatient drug cost, as well as the proportion of drug revenue in total healthcare revenue (drug proportion). The calculations of related indicators are as follows:

i) Drug revenue was obtained directly from the audited financial statement;

ii) Per capita outpatient drug cost $=$ total outpatient drug revenue/total number of outpatients;

iii) Per capita inpatient drug cost $=$ total inpatient drug revenue/total number of inpatients;

iv) Proportion of drug revenue in total healthcare revenue $(\%)=($ pharmaceutical revenue $/$ total healthcare revenue) $* 100 \%$.

\subsection{Statistical analysis}

Interrupted time series (ITS) design was employed to assess the change of drug-related expenditures in 2015-2018 based on pre-intervention and postintervention data collected monthly from 24 tertiary public hospitals, so as to evaluate the actual effects of intervention policy. ITS design has been regarded as the strongest, quasi-experimental methodology to analyze longitudinal effects, which can overcome the shortcomings of simple pre- and post-evaluation, and have an advantage of evaluating intervention effects simultaneously from the level change of observed indicators before and after intervention, and the trend change (slope change) $(32,33)$.

Segmented regression model was used in an interrupted time series analysis to assess the impact of FBM policy and ZMD policy. The data were divided into two segments, that is before intervention and after intervention. Level and trend were used to define each segment of a time series. Specifically, the level is the

Table 1. General characteristics of healthcare institutions in this study

\begin{tabular}{lcccc}
\hline Category & Institutions (number) & Beds (number) & Outpatients (million) & Discharged patients (million) \\
\hline Comprehensive hospitals & 9 & 15,992 & 31.7385 & 0.9599 \\
Chinese medicine hospitals & 4 & 4,224 & 11.9284 & 0.2077 \\
Specialized hospitals & 11 & 7,464 & 12.0858 & 3.0572 \\
$\quad$ Maternity hospitals & 2 & 1,333 & 4.1806 & 0.4262 \\
Children's hospitals & 2 & 1,389 & 4.8480 & 0.0865 \\
Other specialized hospitals & 7 & 4,742 & 55.7527 \\
Total & 24 & 27,680 & & 0.2256 \\
\hline
\end{tabular}


value at the beginning of a segment and trend (slope) is the rate of change during a segment. Both changes in the level following intervention implementation and trend that occurred after intervention can be observed by applying a segmented regression model. The vast strength of this model is evaluating the level changes and trend (slope) changes associated with intervention on the basis of controlling for baseline level and trend (slope) (33).

Two intervention points were included in this study. One is FPM policy (intervention with mark-up) and the other is ZMD policy (intervention without mark-up). The fit level and slope change model:

$$
Y_{i}=\beta_{0}+\beta_{1} X_{1}+\beta_{2} X_{2}+\sum \beta_{j} X_{j}+\varepsilon_{i}
$$

$Y_{i}$ represents the outcome indicator during a time period which changes on a monthly basis between January 2015 until December 2018 for hospital; $X_{1}$ represents trend (slope), pre-intervention is $X_{1}=0$, postintervention is $X_{1}=1 ; X_{2}$ is the intervention measure, pre-intervention is $X_{2}=0$, post-intervention is $X_{2}=1 ; \beta_{1}$ represents the trend change (slope change), $\beta_{2}$ represents the level change; $\sum \beta_{j} X_{j}$ represents covariates (influential factors outside of the intervention measure and time); $\varepsilon_{i}$ represents error. Durbin-Watson test was used to check for serial autocorrelation of the error terms, and $p$ values and coefficients were estimated by use of the least squares method $(33,34)$.

\section{Results}

3.1. Overall change of drug-related expenditures between 2015 and 2018

Seeing from Table 2, the increase of $6.8 \%, 4.5 \%$ and $9.6 \%$ were still observed respectively in total drug revenue, outpatient drug revenue and inpatient drug revenue after implementing FPM policy in 2016. After implementing ZMD policy, a decline of $2.0 \%$ was observed in total drug revenue in 24 tertiary public hospitals in 2017 (compared with 2016), while an increase of $2.7 \%$ was found in total drug revenue in 2018 (compared with 2017). Besides, a decline of $2.5 \%$ was observed in 2017 (compared with 2016) in outpatient drug revenue while an increase of 5.4\% was found in 2018 (compared with 2017), and a decline of $1.5 \%$ was observed in 2017 (compared with 2016) in inpatient drug revenue and a continuous decrease still existed in 2018.

There was no decline in per capita outpatient drug cost in 24 tertiary public hospitals after implementing FPM policy in 2016. After ZMD policy was implemented, a decrease of $4.6 \%$ was observed in 2017 (compared with 2016), but then increased in 2018. For per capita inpatient drug cost, a decline of $1.2 \%$ was found after implementing FPM policy in 2016 (compared with 2015). After implementing ZMD policy, a significant decrease of $9.0 \%$ was found in 2017 (compared with 2016), and a continuous decline was observed in 2018.

The initial drug proportion in 24 tertiary public hospitals was $37.5 \%$ in 2015. After implementing FPM policy, drug proportion in 2016 was $35.3 \%$ (declined by $2.2 \%$ ). After ZMD policy was implemented, the proportion decreased by $4.1 \%$ in 2017 (compared with 2016), and a continuous decline was observed in 2018. It was obvious to see that ZMD policy achieved larger effects on declining drug proportion than FPM policy (Table 2).

\subsection{Results of the segmented regression analysis}

As shown in Table 3, it was observed that drug revenue decreased immediately after implementing FPM policy and an increasing trend change was found though there was no statistical significance (coefficient $=-69.06, p$ $=0.993$; coefficient $=754.95, p=0.156$, respectively), indicating that FPM policy made no significant changes on drug revenue. After implementing ZMD policy, an immediate decline change and an increasing trend change was observed in drug revenue (coefficient $=$ $-11,547.50, p=0.062$; coefficient $=586.30, p=0.038$, respectively).

It was observed that the per capita outpatient

Table 2. Drug revenue, per capita drug cost and drug proportion in 24 tertiary public hospitals between 2015-2018

\begin{tabular}{|c|c|c|c|c|c|c|c|}
\hline \multirow{2}{*}{ Indicator } & \multicolumn{4}{|c|}{ Drug-related expenditures } & \multicolumn{3}{|c|}{ Relative Ratio with Fixed Base/proportion change } \\
\hline & 2015 & 2016 & 2017 & 2018 & $2016 / 2015$ & $2017 / 2015$ & $2018 / 2015$ \\
\hline \multicolumn{8}{|l|}{ Drug revenue (million) } \\
\hline Total & $1,405,269$ & $1,500,859$ & $1,470,348$ & $1,510,502$ & 1.068 & 1.046 & 1.075 \\
\hline Outpatient & 759,956 & 793,881 & 774,300 & 815,864 & 1.045 & 1.019 & 1.074 \\
\hline Inpatient & 645,313 & 706,978 & 696,048 & 694,638 & 1.096 & 1.079 & 1.076 \\
\hline \multicolumn{8}{|l|}{ Per capita drug cost (RMB) } \\
\hline Outpatient & 151 & 151 & 144 & 146 & 1.001 & 0.951 & 0.968 \\
\hline Inpatient & 5,308 & 5,243 & 4,770 & 4,358 & 0.988 & 0.899 & 0.821 \\
\hline \multicolumn{8}{|l|}{ Drug proportion (\%) } \\
\hline Comprehensive hospitals & 37.3 & 35.3 & 31.0 & 28.6 & -2.0 & -6.3 & -8.7 \\
\hline Chinese medicine hospitals & 38.0 & 36.3 & 31.2 & 27.1 & -1.7 & -6.8 & -10.9 \\
\hline Specialized hospitals & 37.6 & 34.9 & 31.8 & 29.9 & -2.7 & -5.7 & -7.7 \\
\hline Total & 37.5 & 35.3 & 31.2 & 28.7 & -2.1 & -6.2 & -8.8 \\
\hline
\end{tabular}


drug cost and per capita inpatient drug cost increased immediately after FPM policy though there was no statistical significance (coefficient $=0.85, p=0.905$; coefficient $=73.63, p=0.548$, respectively). Meanwhile, an increasing trend was found in per capita outpatient drug cost and a declining trend was observed in per capita inpatient drug cost with no statistical significance (coefficient $=0.08, p=0.867$; coefficient $=-12.18, p=$ 0.157 , respectively). After implementing ZMD policy, per capita outpatient drug cost and per capita inpatient drug cost decreased immediately (coefficient $=-12.21, p$ $=0.025$; coefficient $=-226.40, p=0.112$, respectively). Meanwhile, an increasing trend change and a declining trend change were observed in per capita outpatient drug cost and per capita inpatient drug cost (coefficient $=0.27$, $p=0.268$; coefficient $=-25.12, p<0.001$, respectively).

A decline with no statistical significance was observed in drug proportion immediately after implementing FPM policy, and a downward trend was presented in the long run (coefficient $=$ $-0.0001, p=0.992$; coefficient $=-0.0017, p=0.031$, respectively). The implementation of ZMD policy was associated with a significant level decline in the drug proportion (coefficient $=-0.0256, p=0.001$ ), and continuously showed a significant downward trend (coefficient $=-0.0018, p<0.001$ ) (Table 3).

\section{Discussion}

To the best of our knowledge, it was the first study that attempted to simultaneously explore the intervention effects caused by FPM policy and ZMD policy using an interrupted time series design in tertiary public hospital settings. There is little empirical evidence on the comparison of different mark-up policies on declining drug-related expenditures. Overall, the ZMD policy achieved better intervention effects compared with FPM policy.

This study demonstrated that FPM policy made no significant effects on drug-related expenditures (except for the decreasing trend on drug proportion), while ZMD policy significantly declined drug proportion, and the level of per capita outpatient drug cost as well as the trend of per capita inpatient drug cost. It was obvious to see that ZMD policy was more powerful and intensive than FPM policy, which may result from the more thorough separation of provider compensation from the prescription and sales. Due to the existence of mark-up, FPM policy still retained some profit space, which allowed physicians to seek avenues of earning profits. After eliminating all possible profit space on drugs, hospitals may shift attention to other high value medical consumables or clinical processes and seek

Table 3. Results of change in drug-related expenditures pre- and post- the first intervention and final intervention

\begin{tabular}{|c|c|c|c|c|c|}
\hline Indicator & Variable & $\beta$ & S.E. & $\mathrm{T}$ & $p$ \\
\hline \multicolumn{6}{|l|}{ Pre- and post- the first intervention } \\
\hline \multirow[t]{3}{*}{ drug revenue } & (Intercept) & $111,230.29$ & $4,200.88$ & 26.478 & $0.000^{* * * *}$ \\
\hline & $\mathrm{X}_{1}$ & 754.95 & 514.44 & 1.468 & 0.156 \\
\hline & $\mathrm{X}_{2}$ & -69.06 & $7,473.40$ & -0.009 & 0.993 \\
\hline \multirow[t]{3}{*}{ per capita outpatient drug cost } & (Intercept) & 152.62 & 3.98 & 38.330 & $0.000^{* * * *}$ \\
\hline & $\mathrm{X}_{1}$ & 0.08 & 0.49 & 0.170 & 0.867 \\
\hline & $\mathrm{X}_{2}$ & 0.85 & 7.08 & 0.120 & 0.905 \\
\hline \multirow[t]{3}{*}{ per capita inpatient drug cost } & (Intercept) & $5,394.91$ & 67.88 & 79.476 & $0.000^{* * * *}$ \\
\hline & $\mathrm{X}_{1}$ & -12.18 & 8.31 & -1.466 & 0.157 \\
\hline & $\mathrm{X}_{2}$ & 73.63 & 120.76 & 0.610 & 0.548 \\
\hline \multirow[t]{3}{*}{ Drug proportion } & (Intercept) & 0.3880 & 0.0061 & 63.660 & $0.000^{* * * *}$ \\
\hline & $\mathrm{X}_{1}$ & -0.0017 & 0.0007 & -2.310 & $0.031^{*}$ \\
\hline & $\mathrm{X}_{2}$ & -0.0001 & 0.0108 & -0.010 & 0.992 \\
\hline \multicolumn{6}{|l|}{ Pre- and post- the final intervention } \\
\hline \multirow[t]{3}{*}{ drug revenue } & (Intercept) & $114,280.70$ & $5,646.50$ & 20.239 & $0.000^{* * *}$ \\
\hline & $\mathrm{X}_{1}$ & 586.30 & 272.10 & 2.155 & $0.038^{*}$ \\
\hline & $\mathrm{X}_{2}$ & $-11,547.50$ & $5,989.30$ & -1.928 & 0.062 \\
\hline \multirow[t]{3}{*}{ per capita outpatient drug cost } & (Intercept) & 147.01 & 4.91 & 29.963 & $0.000^{* * * *}$ \\
\hline & $\mathrm{X}_{1}$ & 0.27 & 0.24 & 1.127 & 0.268 \\
\hline & $\mathrm{X}_{2}$ & -12.21 & 5.20 & -2.346 & $0.025^{*}$ \\
\hline \multirow[t]{3}{*}{ per capita inpatient drug cost } & (Intercept) & $5,707.84$ & 130.64 & 43.692 & $0.000^{* * * *}$ \\
\hline & $\mathrm{X}_{1}$ & -25.12 & 6.29 & -3.991 & $0.000^{* * * *}$ \\
\hline & $\mathrm{X}_{2}$ & -226.40 & 138.57 & -1.634 & 0.112 \\
\hline \multirow[t]{3}{*}{ Drug proportion } & (Intercept) & 0.3884 & 0.0067 & 58.143 & $0.000^{* * * *}$ \\
\hline & $\mathrm{X}_{1}$ & -0.0018 & 0.0003 & -5.438 & $0.000^{* * * *}$ \\
\hline & $\mathrm{X}_{2}$ & -0.0256 & 0.0071 & -3.615 & $0.001^{* *}$ \\
\hline
\end{tabular}

${ }^{*} p<0.05 ;{ }^{* *} p<0.01 ;{ }^{* * *} p<0.001$. Durbin-Watson test all indicated no autocorrelation.The first intervention study period was between January 2015 to January 2017, where pre-intervention was from January 2015 to December 2015 and post-intervention was from January 2016 to January 2017.The final intervention study period was between January 2016 to December 2018, where pre-intervention was from January 2016 to January 2017 and post-intervention was from February 2017 to December 2018. 
for other price adjustments to compensate for the loss of revenue (35). Judging from this, a comprehensive mark-up-cancellation approach was more likely to bring about better intervention results, which have also been previously demonstrated (25). A separation reform in Taiwan also effectively reduced drug expenditure and changed prescribing behavior, which is consistent with our findings (36).

However, the intervention effects of ZMD policy on drug revenue and per capita drug cost were limited, especially on the trend of drug revenue and per capita outpatient drug cost in the long run. Similar findings also existed in previous studies. $\mathrm{He} \mathrm{YZ}$ et $a l$. found that drug expenditure declined sharply after ZMD policy initially, but the effects of ZMD policy gradually disappeared and became even worse in the long run, except for inpatient drug expenditure (11). Lee $e t$ al. assessed the effects of separation reform on drug expenditures and found medication expenditures increased by $98.4 \%$ for peptic-ulcer medication, among which expensive drugs and branded drugs accounted for the majority of this increase, even when generic drugs were available (37). Similar phenomena also occurred in China, with the fact that physicians tend to prescribe branded drugs that may be more effective but expensive to ensure quick recovery of their patients. Besides, with the population ageing, the number of elderly patients is growing rapidly, who may require more medication therapies, thus drug revenue was difficult to decrease overall. In addition, with the more comprehensive population coverage and further improvement of the medical insurance system, patients with insurance are more likely to be prescribed more drugs than before, and inpatients tend to have more prescriptions than outpatients due to a higher medical reimbursement rate $(38,39)$.

There are some limitations in this study. First, FPM policy (the first intervention with mark-up) and ZMD policy (the final intervention without mark-up) were selected to represent two typical types of intervention measures, while other possibly relevant intervention measures that occurred during the period were not included in analysis. Second, Segmented regression was used to respectively evaluate the effects of the first intervention and the final intervention, while an integrated regression simultaneously including the first and final intervention was not applied due to other possibly relevant interventions that may have also occurred during that period. Third, indicators related to rational drug use were not included for analysis because the data was not available.

In conclusion, this study represents a segmented regression analysis of different mark-up drug policy on drug-related expenditures. Overall, ZMD policy achieved better intervention effects than FPM policy, especially on declining drug proportion. However, expected intervention effects on drug revenue and per capita drug cost were limited and further regulation should be strengthened in the future.

\section{Acknowledgements}

We thank Associate Prof. Zhi-Jie Zhang, and postgraduate Jian $\mathrm{Hu}$, Department of Epidemiology, School of Public Health, Fudan University, for their help in the statistical analysis of this article.

\section{References}

1. Ofori-Asenso R, Agyeman AA. Irrational use of medicines - A summary of key concepts. Pharmacy (Basel). 2016; 4,35 .

2. Mao W, Vu H, Xie Z, Chen W, Tang S. Systematic review on irrational use of medicines in China and Vietnam. PLoS One. 2015; 10:e0117710.

3. Hitchen L. Adverse drug reactions result in 250,000 UK admissions a year. BMJ. 2006; 332:1109.

4. World Health Organization. Measuring medicine prices, availability, affordability and price components 2 nd edition. 2008; http://www.haiweb.org/medicineprices/ manual/documents.html (accessed September 1, 2019).

5. Ben-Aharon O, Shavit O, Magnezi R. Does drug priceregulation affect healthcare expenditures. Eur J Health Econ. 2017; 18:859-867.

6. OECD/WHO. Pharmaceutical expenditure, in OECD/ WHO. Health at a Glance: Asia/Pacific 2012. Paris: OECD Publishing. http://dx.doi.org/10.1787/9789264183902-32en (Accessed November 27, 2019)

7. Chen Y, Hu S, Dong P, Kornfeld A, Jaros P, Yan J, Ma F, Toumi M. Drug pricing reform in China: analysis of piloted approaches and potential impact of the reform. J Mark Access Health Policy. 2016; 4:30458.

8. le Grand A, Hogerzeil HV, Haaijer-Ruskamp FM. Intervention research in rational use of drugs: A review. Health Policy Plan. 1999; 14:89-102.

9. Yu X, Li C, Shi Y, Yu M. Pharmaceutical supply chain in China: Current issues and implications for health system reform. Health Policy. 2010; 97:8-15.

10. Vijayakumar TM, Sathyavati D, Subhashini T, Grandhi S, Dhanaraju MD. Assessment of prescribing trends and rationality of drug prescribing. International Journal of Pharmacology. 2011; 7:140-143.

11. He Y, Dou G, Huang Q, Zhang X, Ye Y, Qian M, Ying X. Does the leading pharmaceutical reform in China really solve the issue of overly expensive healthcare services? Evidence from an empirical study. PLoS One. 2018; 13 : e0190320.

12. Yip W, Mahal A. The health care systems of China and India: performance and future challenges. Health Aff (Millwood). 2008; 27:921-932.

13. Kwon S. Pharmaceutical reform and physician strikes in Korea: separation of drug prescribing and dispensing. Soc Sci Med. 2003; 57:529-538.

14. Yi H, Miller G, Zhang L, Li S, Rozelle S. Intended and unintended consequences of China's zero markup drug policy. Health Aff (Millwood). 2015; 34:1391-1398.

15. Grandfils N. Drug price setting and regulation in France. 2008; http://www.irdes.fr/EspaceAnglais/Publications/ WorkingPapers/DT16DrugPriceSettingRegulationFran ce.pdf (accessed October 20, 2019). 
16. Rockoff H. Price controls. http://www.econlib.org/library/ Enc/PriceControls.html (accessed November 1, 2019)

17. Ess SM, Schneeweiss S, Szucs TD. European healthcare policies for controlling drug expenditure. Pharmacoeconomics. 2003; 21:89-103.

18. Lee IH, Bloor K, Hewitt C, Maynard A. International experience in controlling pharmaceutical expenditure: influencing patients and providers and regulating industry - a systematic review. J Health Serv Res Policy. 2015; 20:52-59.

19. Tiong JJ, Mai CW, Gan PW, Johnson J, Mak VS. Separation of prescribing and dispensing in Malaysia: the history and challenges. Int J Pharm Pract. 2016; 24:302305.

20. Teng CL, Nik-Sherina H, Ng CJ, Chia YC, Atiya AS. Antibiotic prescribing for childhood febrile illness by primary care doctors in Malaysia. J Paediatr Child Health. 2006; 42:612-617.

21. Trap B, Hansen EH, Hogerzeil HV. Prescription habits of dispensing and non-dispensing doctors in Zimbabwe. Health Policy Plan. 2002; 17:288-295.

22. Lopez Bastida J, Mossialos E. Pharmaceutical expenditure in Spain: cost and control. Int J Health Serv. 2000; 30:597616.

23. Li X, Lu J, Hu S, Cheng KK, De Maeseneer J, Meng Q, Mossialos E, Xu DR, Yip W, Zhang H, Krumholz $\mathrm{HM}$, Jiang L, Hu S. The primary health-care system in China. Lancet. 2017; 390: 2584-2594.

24. Yang C, Shen Q, Cai W, Zhu W, Li Z, Wu L, Fang Y. Impact of the zero-markup drug policy on hospitalization expenditure in western rural China: an interrupted time series analysis. Trop Med Int Health. 2017; 22:180-186.

25. Liu Y, Lin Z, Ru Y, Zhang M. Small-scale or fullscale? The zero mark-up drug policy in China. Journal of Interdisciplinary Mathematics. 2017; 20:1167-1178.

26. Shanghai Municipal Bureau of Health. Annual Report of the Health Status of Shanghai. 2017; http://tjj.sh.gov. cn/tjnj/nj18.htm?d1=2018tjnj/C0201.htm (accessed September 20, 2019)

27. National Bureau of Statistics. China Statistical Yearbook. 2008; http://www.stats.gov.cn/tjsj/ndsj/2018/indexch.htm (accessed September 20, 2019).

28. World Bank. New country classifications by income level: 2017-2018. 2017; http://blogs.worldbank.org/opendata/ new-country-classifications-income-level-2017-2018 (accessed July 1, 2019)

29. Lin H, Dyar OJ, Rosales-Klintz S, Zhang J, Tomson G, Hao M, Stålsby Lundborg C. Trends and patterns of antibiotic consumption in Shanghai municipality, China: a 6 year surveillance with sales records, 2009-14. J Antimicrob Chemother. 2016; 71:1723-1729.
30. Tang Y, Liu C, Zhang Z, Zhang X. Effects of prescription restrictive interventions on antibiotic procurement in primary care settings: a controlled interrupted time series study in China. Cost Eff Resour Alloc. 2018; 16:1.

31. Xu GC, Zheng J, Zhou ZJ, Zhou CK, Zhao Y. Comparative study of three commonly used methods for hospital efficiency analysis in Beijing tertiary public hospitals, China. Chin Med J (Engl). 2015; 128:31853190.

32. Bernal JL, Cummins S, Gasparrini A. Interrupted time series regression for the evaluation of public health interventions: a tutorial. Int J Epidemiol. 2017; 46:348355.

33. Wagner AK, Soumerai SB, Zhang F, Ross-Degnan D. Segmented regression analysis of interrupted time series studies in medication use research. J Clin Pharm Ther. 2002; 27:299-309.

34. Durbin J, Watson GS. Testing for serial correlation in least square regression. I. Biometrika. 1950; 37:409-428.

35. Liu X, Xu J, Yuan B, Ma X, Fang H, Meng Q. Containing medical expenditure: lessons from reform of Beijing public hospitals. BMJ. 2019; 365:12369.

36. Chou YJ, Yip WC, Lee CH, Huang N, Sun YP, Chang HJ. Impact of separating drug prescribing and dispensing on provider behaviour: Taiwan's experience. Health Policy Plan. 2003; 18:316-329.

37. Lee EK, Malone DC. Comparison of peptic-ulcer drug use and expenditures before and after the implementation of a government policy to separate prescribing and dispensing practices in South Korea. Clin Ther. 2003; 25:578-592.

38. Sun X, Jackson S, Carmichael GA, Sleigh AC. Prescribing behaviour of village doctors under China's New Cooperative Medical Scheme. Soc Sci Med. 2009; 68: 1775-1779.

39. Zhang $\mathrm{H}, \mathrm{Hu} \mathrm{H}, \mathrm{Wu} \mathrm{C}, \mathrm{Yu} \mathrm{H}$, Dong $\mathrm{H}$. Impact of China's public hospital reform on healthcare expenditures and utilization: a case study in ZJ Province. PLoS One. 2015; 10:e 0143130

Received December 30, 2019; Revised February 6, 2020; Accepted February 12, 2020

${ }^{\S}$ These authors contributed equally to this work.

*Address correspondence to:

Yingyao Chen, Key Lab of Health Technology Assessment, National Health Commission, School of Public Health, Fudan University, Shanghai 200032, China.

E-mail: yychen@shmu.edu.cn

Released online in J-STAGE as advance publication February 25,2020 . 